OPEN ACCESS

Edited by:

Ronald Halim,

University College Dublin, Ireland

Reviewed by:

Letícia Assis,

Universidade Federal de Viçosa, Brazil

Diva De Souza Andrade,

Instituto Agronômico do Paraná, Brazil

Pabulo Henrique Rampelotto,

Federal University of Rio Grande do

Sul, Brazil

*Correspondence:

Jonathan L. Wood

jlwood@mail.bradley.edu

Specialty section:

This article was submitted to

Bioenergy and Biofuels,

a section of the journal

Frontiers in Energy Research

Received: 13 September 2021

Accepted: 05 January 2022

Published: 25 January 2022

Citation:

Wood JL, Takemoto JY and Sims RC (2022) Rotating Algae Biofilm Reactor for Management and Valorization of

Produced Wastewater.

Front. Energy Res. 10:774760.

doi: 10.3389/fenrg.2022.774760

\section{Rotating Algae Biofilm Reactor for Management and Valorization of Produced Wastewater}

\author{
Jonathan L. Wood ${ }^{1 *}$, Jon Y. Takemoto ${ }^{2}$ and Ronald C. Sims ${ }^{1}$ \\ ${ }^{1}$ Department of Biological Engineering, Sustainable Waste-to-Bioproduct Engineering Center, Utah State University, Logan, UT, \\ United States, ${ }^{2}$ Department of Biology, Utah State University, Logan, UT, United States
}

Production and enhancement of high value phycocyanin pigment from microalgae biofilms cultured on oilfield and natural gas produced wastewater were investigated. Cyanobacteria isolated from Logan City, Utah, wastewater treatment Lagoons (LLC2) was cultured in produced water using rotating algal biofilm reactors (RABRs). The RABRs were operated under "low" and "high" light conditions and biomass and phycocyanin content were compared. Phycocyanin content was enhanced by growth under low light conditions to a maximum yield of $31.7 \mathrm{mg} / \mathrm{g}$ ash-free dry weight (AFDW) biomass for an $87.6 \%$ increase in phycocyanin yield. Phycocyanin productivity was equivalent for both the low and high light treatments $(327 \pm 81$ and $305 \pm 39 \mathrm{mg} / \mathrm{m}^{2} /$ day, respectively), due to the significantly lower AFDW biomass productivity of the low light treatment $\left(2.7 \pm 0.4 \mathrm{~g} / \mathrm{m}^{2}\right.$-day). An indoor laboratory evaluation of 14 substrata for biofilm growth showed that cotton rope and cotton belt material provided the highest biomass yields. Further evaluation in a pilot-scale outdoor produced wastewater pond showed that the biomass characteristics from the two substrata differed. The corrugated surface area of the cotton rope cultured a biofilm with a large community of non-photosynthetic organisms with an autotrophic index of 507 and a low phycocyanin yield of $3.4 \mathrm{mg} / \mathrm{g}$ AFDW. However, the cotton belt substratum cultured a healthy photosynthetic biofilm with an autotrophic index of 127 and a phycocyanin yield of $47.0 \mathrm{mg} / \mathrm{g}$ AFDW. These results demonstrate the cultivation of microalgae biomass and valorization of oilfield and natural gas produced wastewater through the design and management of algal-based biofilm photobioreactors.

Keywords: photobioreactor, cyanobacteria, phycocyanin, microalgae biofilm, produced wastewater, rotating algal biofilm reactor

\section{INTRODUCTION}

"Produced wastewater" disposal from oil and natural gas extraction is a growing problem in the United States and around the world. Oil extraction in the United States generates an average ratio of over 10:1 L of produced water to oil, for an average of just over 3.3 million megaliters of produced water (Clark and Veil, 2015). Aging wells in arid regions such as Texas accounted for the largest portions of produced water generated. Over $91 \%$ of this wastewater is reinjected in disposal wells or into formations for enhanced recovery while much of the remainder is stored in lined ponds before 
further treatment (Clark and Veil, 2015). Produced water represents an opportunity for algal cultivation for nutrient recycling and beneficial use of the biomass generated.

Sullivan Graham et al. (2017) conducted a thorough review on produced water as a growth medium for microalgal cultivation for nutrient recycling. They found that although produced water can have high salinity ranges and organic chemical constituents detrimental to growth of microalgae, it has the advantage of containing inorganic nutrients needed for microalgal growth. The also indicate that microalgal cultivation in produced water represents an opportunity for wastewater treatment and biofuels generation (Sullivan Graham, et al., 2017). The potential for using produced water as a microalgal cultivation medium to remove nutrients is addressed in a recent and comprehensive review by Rahman, et al. (2020). Most report using endogenous environmental microbes, highlighting the need to explore microalgal strains optimized for produced water chemical compositions (Arriada and Abreu, 2014; Godfrey, 2012; Winckelmann et al., 2015).

Currently, most of the investigations into produced water as a cultivation medium focus on microalgae as a biofuel feedstock with limited published work on generating high value bioproducts (Wood et al., 2015). High value bioproduct side streams can be integrated into a microalgal biorefinery to potentially improve the economics of produced water treatment using microalgal biomass and derived biofuels to offset capital costs (Chew et al., 2017).

Within the context of using produced water as a resource for production of high value products from microalgae, phycobiliproteins and their derivatives have been identified as high value products and their recovery can be integrated into a microalgae biorefinery operation (Chew et al., 2017). Phycobiliproteins are water soluble and their easy extraction in biorefinery operations will have minimal impacts on the recovery efficiencies of energy dense lipids. In cyanobacteria, phycobiliproteins are assembled in large complexes (phycobilisomes) that harvest and funnel light energy to chlorophyll. The phycobiliprotein phycocyanin is used as a natural blue food dye as well as a laboratory fluorescent agent; and it also has antioxidant, antitumor, antiviral, and antiinflammatory effects (Chew et al., 2017; Eriksen, 2008). Phycocyanin's brilliant blue color is due to its phycocyanobilin chromophore. In addition to color, phycocyanin derives many of its therapeutic effects from phycocyanobilin (Chew et al., 2017; Eriksen, 2008; Marín-Prida et al., 2013). Therapeutic compositions of phycocyanobilin have been reported to be effective at low micromolar concentrations, making them potent antioxidants (Hirata et al., 2000).

In limited light conditions, Oscillitoriales cyanobacteria increase the size and number of phycobilisomes present on their cellular thylakoid membranes to maximize light energy capture for photosynthesis (Chaneva et al., 2007; Eriksen, 2008). This biological strategy is complemented by using the high efficiency energy absorption and transfer capabilities of phycobilisome phycocyanin in the upper red-orange end of the visible light spectrum. Concerning the effect of light intensities on cyanobacteria, Polyzois et al. (2020) tested both growth of Nostoc sp. cyanobacteria and the production of the bioproduct cryptophycin-1 anticancer agent at 80, 120, and $200 \mu \mathrm{mol}$ photon $\mathrm{m}^{-2} \mathrm{~s}^{-1}$ and reported that while yield was statistically equivalent at 80 and $200 \mu \mathrm{mol}$ photon $\mathrm{m}^{-2} \mathrm{~s}^{-1}$ after 10 days, the bioproduct yield was highest and statistically equivalent with 80 and $120 \mu \mathrm{mol}$ photon $\mathrm{m}^{-2} \mathrm{~s}^{-1}$, with declining production of the bioproduct throughout the 10-day period with $200 \mu \mathrm{mol}$ photon $\mathrm{m}^{-2} \mathrm{~s}^{-1}$. Thus, lower light intensity resulted in greater production of the bioproduct. Concerning growth substrates for algae biofilm formation, Christenson and Sims (2012) evaluated over 15 different materials and identified cottonbased options as the best performers. Gross et al. (2013) also identified cotton sheet as the best material for attached algal growth. However, whether cotton cord single stand rope or consolidated cotton belt performs better has remained an area of investigation.

A Rotating Algae Biofilm Reactor (RABR) platform was used as a microalgae photobioreactor for this study due to the presence of high solids content and high turbidity of produced water, and the tendency of cyanobacteria strain LLC2 to form biofilms under different conditions of light and substrata. The RABR can yield a harvested biomass slurry with a solids content of up to $12-16 \%$ with a cotton rope growth substratum (Blanken et al., 2014; Christenson and Sims, 2012; Gross et al., 2013; Sebestyén et al., 2016).

The main purposes of this study were to evaluate the influences of light intensities and growth substrata materials as management tools for biomass and phycocyanin production and quality by RABR microalgae biofilms cultivated in produced water.

\section{MATERIALS AND METHODS}

\section{Laboratory Growth Conditions}

Logan Lagoons Cyanobacteria selection 2 (LLC2), described previously (Wood et al., 2015), was cultured using $1 \mathrm{~L}$ Rotating Algal Biofilm Reactors (RABRs) with a bioreactor areal footprint of $0.0175 \mathrm{~m}^{2}$ (Table 1) (Wood et al., 2015). The bioreactors were fitted with $0.476 \mathrm{~cm}$ dia. solid braid cotton rope (Knot and Rope Supply, Perrysburg, OH) as a growth substratum. Produced water (Southern Cross, Baggs, WY) with a conductivity of $19,400 \mu \mathrm{mhos} / \mathrm{cm}$ was amended with $3.0 \mathrm{~g} / \mathrm{L}$ $\mathrm{NaNO} 3$ and $0.5 \mathrm{~g} / \mathrm{L} \mathrm{K} 2 \mathrm{HPO} 4$ for use as a growth medium. Physical operation was performed as in Christenson and Sims (2012) (Christenson and Sims, 2012; Wood et al., 2015) with $16-21^{\circ} \mathrm{C}$ daily growth medium temperatures. Light was provided on a $14 \mathrm{~h}$ on: $10 \mathrm{~h}$ off cycle by $1000 \mathrm{~W}$ sodium vapor lamps and fluorescent bulbs fitted with neutral density filters (Rosco, Sun Valley, CA) to provide "low" (40 $\mu \mathrm{mol}$ photons $\left.\mathrm{m}^{-2} \mathrm{~s}^{-1} \mathrm{PAR}\right)$ and "high" light $(220 \mu \mathrm{mol}$ photons $\mathrm{m}^{-2} \mathrm{~s}^{-1}$ PAR) growth conditions. The value of $220 \mu \mathrm{mol}$ photons $\mathrm{m}^{-2} \mathrm{~s}^{-1} \mathrm{PAR}$ was chosen as a "high" treatment to stay below photoinhibitory light levels. An inoculum ( $1 \mathrm{~g}$ centrifuged wet weight) of LLC2, previously grown in produced water medium, was added to the bioreactors before operation. 
TABLE 1 | Rotating algae biofilm reactors for biomass and phycocyanin production from produced water-based media.

\begin{tabular}{|c|c|c|c|}
\hline Parameter & Indoor laboratory & Greenhouse & Outdoor pilot scale \\
\hline Liquid volume & $1 \mathrm{~L}$ & $8 \mathrm{~L}$ & $2,000 \mathrm{~L}$ \\
\hline Materials (Substratum) for Biofilm growth & Cotton rope & $\begin{array}{l}\text { Cotton rope (control) } \\
\text { Cotton conveyor belt material } \\
12 \text { others }^{a}\end{array}$ & $\begin{array}{l}\text { Cotton rope (control) } \\
\text { Cotton conveyor belt }\end{array}$ \\
\hline Peripheral speed & $2 \mathrm{~cm} / \mathrm{sec}$ & $2 \mathrm{~cm} / \mathrm{sec}$ & $2 \mathrm{~cm} / \mathrm{sec}$ \\
\hline Plan area exposed to Light & $0.0175 \mathrm{~m}^{2}$ & $0.063 \mathrm{~m}^{2}$ & $0.51 \mathrm{~m}^{2}$ \\
\hline Dimensions of RABR & $9 \mathrm{~cm}$ dia.; $20 \mathrm{~cm} \mathrm{~L}$ & $9 \mathrm{~cm}$ dia.; $71 \mathrm{~cm} \mathrm{~L}$ & 56 cm dia.; 89 cm L \\
\hline HRT (batch mode) & 40 days & 29 days & 45 days \\
\hline Specific conductivity & $19,400 \mu \mathrm{mhos} / \mathrm{cm}$ & $19,400 \mu \mathrm{mhos} / \mathrm{cm}$ & $19,400 \mu \mathrm{mhos} / \mathrm{cm}$ \\
\hline Light energy and source & $\begin{array}{l}\text { Fluorescent/sodium vapor bulbs } \\
40 \mu \text { moles } / \mathrm{m}^{2}-\mathrm{s} \\
220 \mu \mathrm{moles} / \mathrm{m}^{2}-\mathrm{s} \\
14 \mathrm{~h} \text { on; } 10 \mathrm{~h} \text { off }\end{array}$ & $\begin{array}{l}\text { Natural sunlight } \\
50 \mu \text { moles } / \mathrm{m}^{2} \text {-s (am) } \\
500 \mu \text { moles } / \mathrm{m}^{2} \text {-s (max) } \\
14 \text { h day; } 10 \text { h night }\end{array}$ & $\begin{array}{l}\text { Natural sunlight } \\
70 \mu \text { moles } / \mathrm{m}^{2}-\mathrm{s}(\mathrm{am}) \\
500 \mu \mathrm{moles} / \mathrm{m}^{2}-\mathrm{s} \text { (max) } \\
14 \mathrm{~h} \text { day; } 10 \mathrm{~h} \text { night }\end{array}$ \\
\hline Temperature & $16-21 \mathrm{C}$ & $16-20 \mathrm{C}$ & $12-30 \mathrm{C}$ \\
\hline Nutrient augmentation ${ }^{\mathrm{b}}$ & $\begin{array}{l}3.0 \mathrm{~g} / \mathrm{L} \mathrm{NaNO} \mathrm{N}_{3} \\
0.5 \mathrm{~g} / \mathrm{L} \mathrm{K}_{2} \mathrm{HPO}_{4}\end{array}$ & $\begin{array}{l}3.0 \mathrm{~g} / \mathrm{L} \mathrm{NaNO}{ }_{3} \\
0.5 \mathrm{~g} / \mathrm{L} \mathrm{K}_{2} \mathrm{HPO}_{4}\end{array}$ & $\begin{array}{l}1.5 \mathrm{~g} / \mathrm{L} \mathrm{NaNO}{ }_{3} \\
0.5 \mathrm{~g} / \mathrm{L} \mathrm{K}_{2} \mathrm{HPO}_{4}\end{array}$ \\
\hline
\end{tabular}

${ }^{a}$ Other substrata tested: four polyester based, five cotton based, one acrylic based, one ethylene vinyl acetate foam, one burlap based.

${ }^{b}$ Nutrients contents are determined by subsurface geochemistry and were $\mathrm{p}=1.5 \mathrm{mg} / \mathrm{L}$ and $\mathrm{N}=0.1 \mathrm{mg} / \mathrm{L}$; for laboratory and greenhouse tests, excess nutrients were added to ensure non-limiting growth conditions; for Outdoor tests, $N$ and $P$ amendments are based on N:P ratios using Redfield Ratio for N:P of 16:1.

\section{Greenhouse RABR Growth Substratum Experiments}

Growth substratum testing was performed using laboratory scale RABRs as in Christenson and Sims (2012) in a greenhouse at Utah State University's Innovation Campus that was conducted under natural diurnal conditions of light and temperature during the month of May where light intensity varied from no light (night) to approximately $500 \mu \mathrm{mol}$ photons $\mathrm{m}^{-2} \mathrm{~s}^{-1}$ PAR during the day and temperature was controlled between 16 and $20^{\circ} \mathrm{C}$ (Table 1). Substrata materials tested for microalgal biofilm biomass yields included four polyester, one acrylic, one ethylene vinyl acetate foam, seven cotton, and one burlap, and were selected based on previous tests by Christenson and Sims (2012) using cotton low thread and high thread. Plastic materials, including polyester, acrylic, and vinyl-based, were tested because these materials are already used in full-scale wastewater treatment systems for other purposes as identified and used by WesTechInc. Environmental Engineering, Salt Lake City, Utah. Specific surface characteristics for the different substrata were not characterized for this research. All materials tested were in a sheet configuration except for the $0.476 \mathrm{~cm}$ dia. cotton rope, which served to compare with results obtained under laboratory growth conditions. After an initial inoculation of LLC2, the biofilms were allowed to seed and develop over a 29-day period before harvesting when temperature could be controlled between 16 and $20 \mathrm{C}$. Biomass yields are reported as the mean of duplicate measurements with error bars showing one standard deviation from the mean.

\section{Outdoor RABR Growth Conditions}

A $2000 \mathrm{~L}$ outdoor produced water pond was constructed at the Algae Processing and Products facility on Utah State University's Innovation Campus in Logan, Utah and operated during the months of August and September, when outdoor temperatures range from 12 to $30 \mathrm{C}$ (Table 1). In order to control for light intensity, the bioreactor units and pond were shaded with Gardener Sun Screen Fabric so that the maximum intensity was $500 \mu \mathrm{mol}$ photons $\mathrm{m}^{-2} \mathrm{~s}^{-1}$ PAR during the day. The pond was filled with produced water from the Southern Cross produced water facility and amended with $1.5 \mathrm{~g} / \mathrm{L} \mathrm{NaNO} 3$ and $0.5 \mathrm{~g} / \mathrm{L} \mathrm{K2HPO}$. The floating RABR unit was constructed with two $0.51 \mathrm{~m}^{2}$ areal footprint drums to compare the biomass characteristics of the two best performing growth substrata materials previously tested, including cotton rope $0.476 \mathrm{~cm}$ dia. and cotton conveyor belt, in an outdoor pond environment. Drum rotation was geared to provide the same peripheral velocity as laboratory scale units. For inoculation, $13 \mathrm{~g}$ wet centrifuged weight of LLC2 cyanobacteria was distributed along the bioreactor surface area. Biomass was harvested using a spool harvester (Christenson and Sims, 2012) for the cotton rope and a flat scraping blade for the conveyor belt material (Christenson and Sims, 2012) after a 45days growth period.

\section{Biomass, Phycocyanin, Phycocyanobilin, and Chlorophyll a Determinations}

Biomass harvested from the growth substratum was lyophilized and powdered for Ash Free Dry Weight (AFDW) and phycocyanin analysis. Percent total solids, ash content, chlorophyll a, and Autotrophic Index of the harvested biomass were performed as in Eaton et al. (2005). Biomass and phycocyanin yields are defined based on surface area available to light exposure.

Phycocyanin (PC) extractions were performed by first resuspending lyophilized powdered biomass in E-Pure deionized water and rehydrating the material for $15 \mathrm{~min}$. The samples were then subjected to two freeze/thaw cycles with a subsequent $2 \mathrm{~h}$ extraction by agitation on a Thermolyne Speci-Mix rocker table (Thermo Fisher Scientific, Waltham, MA). Following centrifugation for $15 \mathrm{~min}$ at $12,000 \mathrm{~g}$, the crude extract supernatant phase was collected and analyzed for PC concentration and extract purity. 


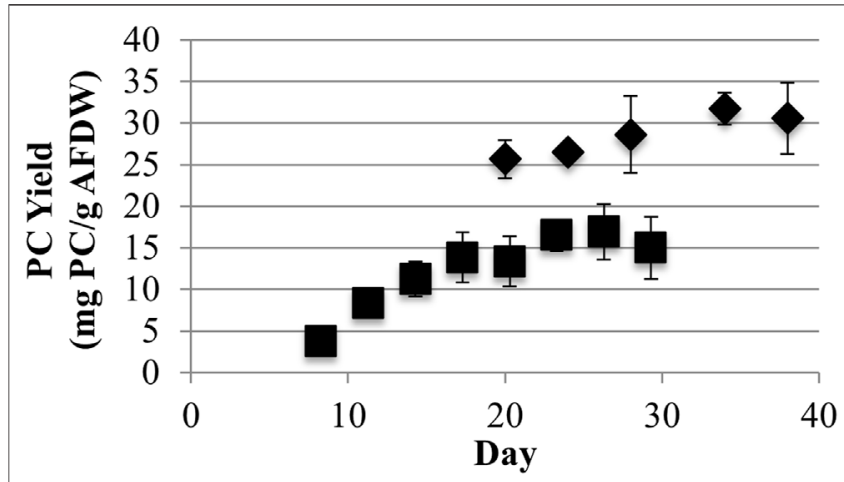

FIGURE 1 | Phycocyanin (PC) Ash Free Dry Weight (AFDW) yields from harvested algal biomass with low (40) ( $)$ and high (220) (-) light ( $\mu$ mol photons $\mathrm{m}^{-2} \mathrm{~s}^{-1} \mathrm{PAR}$ ) growth conditions (one standard deviation shown, $n \geq 3$ ).

PC concentration in the crude extract was determined by the methods of Bennet and Bogorad (1973). PC purity in extracts was measured as the ratio of the optical absorbances at 620 and $280 \mathrm{~nm}$ (Patil et al., 2006). PC yields were calculated as

$$
\frac{\mathrm{mg} \text { PC }}{\mathrm{g} \text { AFDW }}=\frac{\mathrm{mg} \text { PC }}{\mathrm{ml}} * \frac{\text { extraction volume }(\mathrm{ml})}{\text { AFDW of biomass }(\mathrm{g})}
$$

Phycocyanobilin (PCB) was extracted from the unwashed and lyophilized outdoor pond RABR biomass as described previously (Ito, et al., 2013) using 0.05 M sodium phosphate buffer ( $\mathrm{pH} 7$ ) as phycocyanin extraction buffer. The resulting mixture was centrifuged at $4,500 \mathrm{~g}$ and $4^{\circ} \mathrm{C}$ for $90 \mathrm{~min}$ and the crude PC extract was used to form a $50 \%$ saturated solution of ammonium sulfate. After the PC solution was allowed to precipitate for $1 \mathrm{~h}$ at $4^{\circ} \mathrm{C}$, the mixture was centrifuged at $4,500 \mathrm{~g}$ and $4^{\circ} \mathrm{C}$ for $1 \mathrm{~h}$ and the PC pellet was washed with methanol $7 \times$, until the supernatant was clear. The PC pellet was heated at $60^{\circ} \mathrm{C}$ for $16 \mathrm{~h}$ in methanol and centrifuged to obtain the cleaved PCB chromophore in the supernatant. The PCB content of the crude extract was estimated in a $2 \% \mathrm{HCl} /$ methanol solution using a molar attenuation coefficient of $\varepsilon 680=37.9 \mathrm{mM}^{-1} \mathrm{~cm}^{-1}$. (Cole et al., 1967; Cornejos et al., 1992; Zhao et al., 2006).

\section{Statistical Analysis}

Parameters for comparison of cotton belt versus cotton rope substrata was conducted in triplicate with independent measurements. Error bars represent one standard deviation from the mean of the samples taken.

\section{RESULTS}

\section{Laboratory RABR Phycocyanin and Biomass Yields}

Low light LLC2 biofilms produced nearly twice the amount of phycocyanin per biomass amount (maximum of $31.7 \pm 1.9 \mathrm{mg} / \mathrm{g}$ AFDW) compared to high light LLC2 biofilms (Figure 1). The increase in phycocyanin yield during low light treatment was accompanied by an increase in crude extract purity, to just above

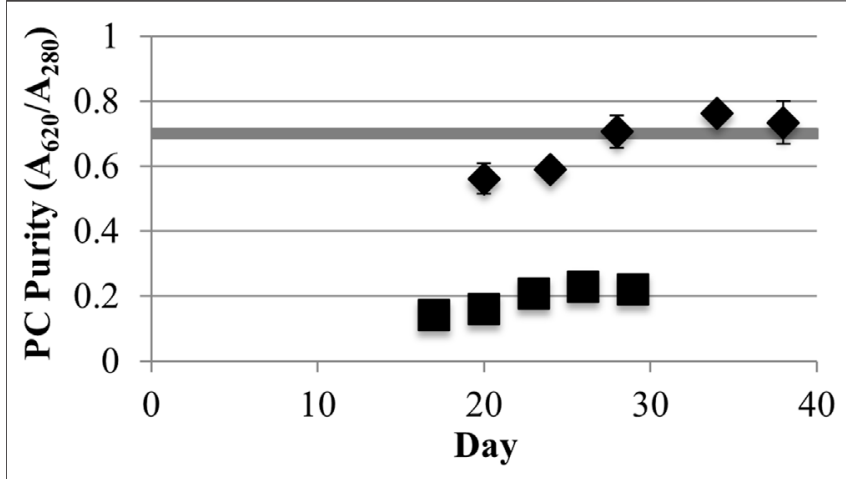

FIGURE 2 | Phycocyanin (PC) purity (A620/A280) from low (40) ( $\bullet$ ) and high (220) (-) light ( $\mu \mathrm{mol}$ photons $\mathrm{m}^{-2} \mathrm{~s}^{-1} \mathrm{PAR}$ ) incidence (one standard deviation shown, $n \geq 3$ ). The shaded horizontal bar shows the minimum limit for food grade purity $\left(A_{620} / A_{280}=0.7\right)$.

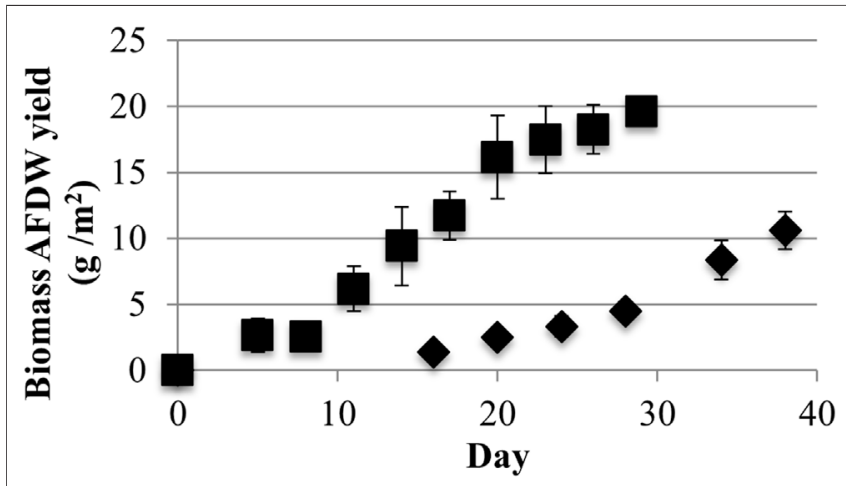

FIGURE 3 | Growth surface area biomass Ash Free Dry Weight (AFDW) yields from low (40) ( ) and high (220) (-) light ( $\mu \mathrm{mol}$ photons $\mathrm{m}^{-2} \mathrm{~s}^{-1} \mathrm{PAR}$ ) conditions (one standard deviation shown, $n \geq 3$ ).

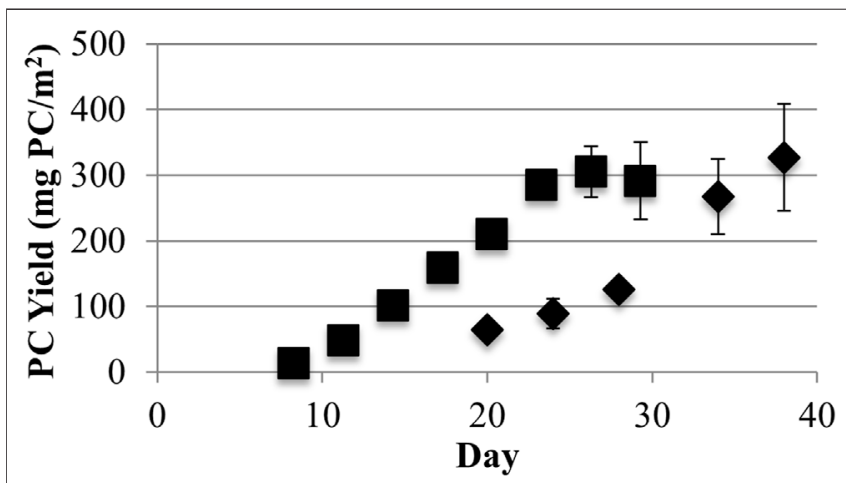

FIGURE 4 | Growth surface area yields of phycocyanin (PC) from low (40) $(\bullet)$ and high (220) (घ) light ( $\mu \mathrm{mol}$ photons $\mathrm{m}^{-2} \mathrm{~s}^{-1} \mathrm{PAR}$ ) conditions (one standard deviation shown, $n \geq 3$ ).

the benchmark standard for food grade quality phycocyanin (Figure 2) (Eriksen, 2008; Rito-Palomares et al., 2001). These results highlight the malleability of the phycobilisome apparatus 


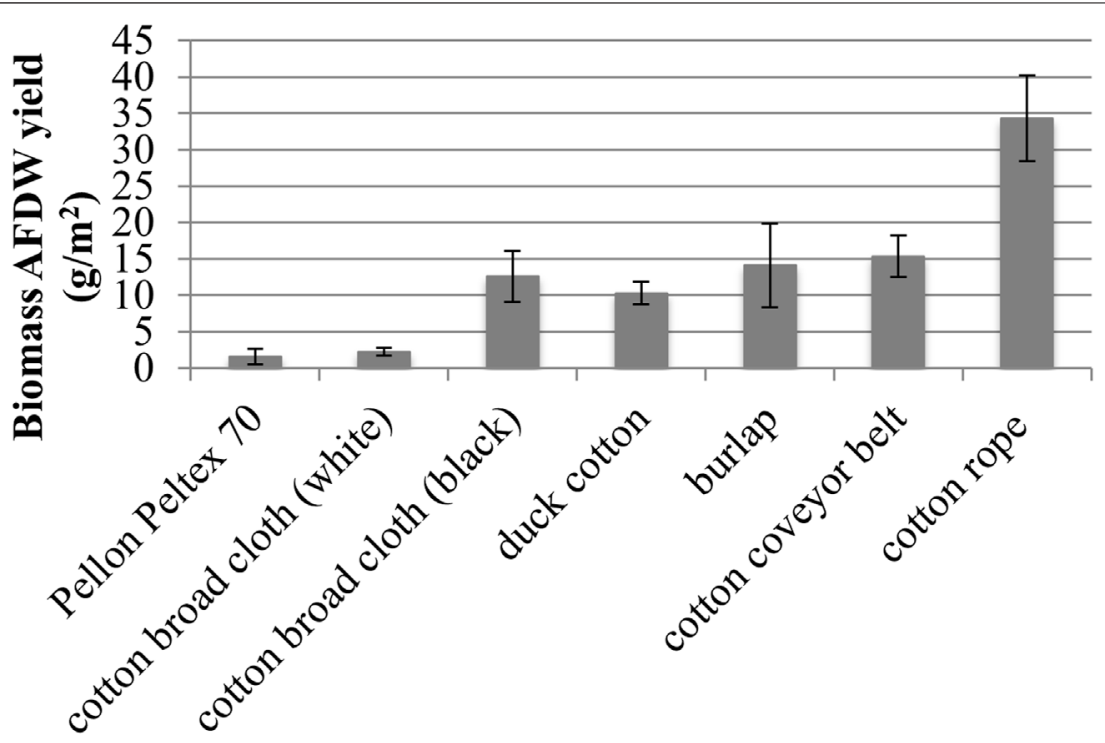

FIGURE 5 | Growth Substratum Evaluation of biomass Ash Free Dry Weight (AFDW) yields ( $\bullet$ ) (one standard deviation shown, $n=2$ ).

to respond to different light intensities that may be configured or controlled at large scale by the RABR photobioreactor design and operation.

LLC2 grown with low light achieved a maximum areal Ash Free Dry Weight (AFDW) biomass productivity of $2.7 \pm 0.4 \mathrm{~g} / \mathrm{m}^{2}$-day and a maximum growth surface area yield of $10.6 \pm 1.4 \mathrm{~g} / \mathrm{m}^{2}$ over a 38-days growth period (Figure 3). In contrast, growth with high light yielded higher ADFW productivity $\left(4.8 \pm 0.7 \mathrm{~g} / \mathrm{m}^{2}\right.$-day $)$ and yield $\left(20+0.5 \mathrm{~g} / \mathrm{m}^{2}\right)$ as compared to cultures grown with low light.

However, similar phycocyanin maximum surface area yields of $327 \pm 81$ and $305 \pm 39 \mathrm{mg} / \mathrm{m}^{2}$ were obtained, respectively, for low and high light (Figure 4). Both light conditions yielded statistically similar phycocyanin areal productivities equivalent to $94.0 \pm 31.4 \mathrm{mg} / \mathrm{m}^{2}$-day during exponential growth based on triplicate independent measurements and using differences greater than one standard deviation from the mean as indicating statistical difference. Therefore, phycocyanin AFDW yields, and purity varied inversely as a function of light intensity, but total phycocyanin productivity did not. As a consequence, different production goals may be achieved by varying the biofilm culture light level. Operations with a high demand for biomass and less need for phycocyanin purity would operate with higher light levels. Conversely, operations with a demand for high purity phycocyanin and less need for biomass would operate under lower light levels. Operating at a low light level would reduce biomass processing costs for high purity phycocyanin extraction by reducing the volumes of processed biomass (Chew et al., 2017).

\section{Greenhouse Growth Substratum Evaluation} Growth substrata were evaluated for biomass growth (Figure 5). Natural materials displayed better biofilm attachment and harvestable growth, as seen in previous studies, over a 29 days growth period (Christenson and Sims, 2012; Gross et al., 2013; Gross and Wen, 2014). Of all substrata tested, hydrophilic cotton rope gave the highest harvestable biomass yield of $34.3 \pm 5.9 \mathrm{~g} / \mathrm{m}^{2}$
AFDW, or a nearly $225 \%$ increase in biomass compared with the next highest biomass yield from cotton conveyor belt material (15.3 \pm $2.8 \mathrm{~g} / \mathrm{m}^{2}$ AFDW). Other hydrophilic natural materials including burlap, black cotton broad cloth, and duck cotton materials gave lower, but measurable, levels of biomass. Black cotton broad cloth yielded five times the AFDW biomass compared with white cotton broad cloth $\left(12.6 \pm 3.5 \mathrm{~g} / \mathrm{m}^{2}\right.$ AFDW and $2.2 \pm 0.5 \mathrm{~g} / \mathrm{m}^{2}$ AFDW, respectively) (Figure 5). Synthetic hydrophobic materials such as polyester, acrylic, and ethylene vinyl acetate did not yield harvestable growth. The exception was Pellon Peltex 70, which provided low levels of harvestable growth at $1.6 \pm 1.0 \mathrm{~g} / \mathrm{m}^{2}$ AFDW.

\section{Outdoor RABR Biomass Composition and Phycocyanobilin Extraction}

Based on the above described results and of other studies (Christenson and Sims, 2012; Gross et al., 2013), cotton rope and cotton conveyor belt materials were selected for experiments with a larger scale floating RABR in an outdoor pond. Biomass harvested from the cotton belt substratum vs. the cotton rope substrata differed greatly in yield and composition at the end of a 45-days growth period (Table 2). The cotton belt material yielded deep blue green biomass with a thick consistency, while the cotton rope yielded biomass in shades of red, brown, and green with a thin watery consistency. Microscopic inspection indicated a large nonalgal microbial community on the rope substrata.

The AFDW growth surface area biomass yield of the cotton rope material $\left(24.2 \mathrm{~g} \mathrm{AFDW} / \mathrm{m}^{2}\right)$ displayed a near $140 \%$ increase in AFDW biomass yield when compared to the cotton belt material $\left(10.1 \mathrm{~g} \mathrm{AFDW} / \mathrm{m}^{2}\right)$, similar to findings with the smaller RABR system in the greenhouse trials. The lower biomass yields of the outdoor RABR compared to yields for the greenhouse RABR may be due to the $10-15^{\circ} \mathrm{C}$ lower average nighttime temperatures observed during the outdoor testing period in AugustSeptember. These results highlight the importance of a regional 
TABLE 2 | Comparison of properties of biomass cultivated on cotton rope versus flat cotton belt substrata on an outdoor floating RABR.

\begin{tabular}{|c|c|c|}
\hline Properties & Westech cloth & Rope \\
\hline Dry biomass yield (g/m²) & 14.7 & 42.1 \\
\hline AFDW biomass yield (g/m²) & 10.1 & 24.2 \\
\hline$\%$ Solids harvested & 6.9 & $4.2 \pm 0.2$ \\
\hline$\%$ Ash content & $31.5 \pm 0.03$ & $42.5 \pm 0.07$ \\
\hline Phycocyanin yield (mg PC/g dry biomass) & $32.2 \pm 0.55$ & $1.9 \pm 0.05$ \\
\hline Phycocyanin yield (mg PC/g wet biomass) & $2.2 \pm 0.04$ & $0.1 \pm 0.002$ \\
\hline Phycocyanin yield (mg PC/g AFDW biomass) & $47.0 \pm 0.80$ & $3.4 \pm 0.09$ \\
\hline Phycocyanin extract purity & $0.432 \pm 0.005$ & $0.077 \pm 0.003$ \\
\hline Chlorophyll a + pheophytin a (mg/m2) & $84.9 \pm 3.77$ & $71.3 \pm 0.69$ \\
\hline Chlorophyll a (mg/g dry biomass) & $5.4 \pm 0.31$ & $1.1 \pm 0.016$ \\
\hline Chlorophyll a (mg/m²) & $79.4 \pm 4.56$ & $47.7 \pm 0.68$ \\
\hline Autotrophic index (Al) & $127 \pm 7.54$ & $507 \pm 7.28$ \\
\hline $664 \mathrm{~nm} / 665 \mathrm{~nm}$ of Chl a extract & $1.67 \pm 0.015$ & 10.10 .015 \\
\hline
\end{tabular}

${ }^{a}$ Average value shown, $\mathrm{n}=3-4$.

and seasonal evaluation of microalgal growth performance when considering outdoor microalgal growth systems.

While the cotton rope substratum produced significantly more AFDW biomass than the cotton conveyor belt material, the rope also displayed $11 \%$ higher ash content and $2.7 \%$ lower percent solids in the recovered biomass when compared to the belt material (Table 2). The higher water content in the harvested rope biomass may be due in part to the spool harvester method of harvesting biomass versus the simplified flat scraper blade used for the belt material. The increased water and ash content of the cotton rope material significantly increases the cost of processing by increasing both the overall process input volumes and the increase in low value waste volumes of ash.

The phycocyanin yield from the two materials differed greatly with the cotton belt material displaying $47.0 \mathrm{mg}$ PC/g AFDW when compared to the cotton rope material at $3.4 \mathrm{mg} \mathrm{PC} / \mathrm{g}$ AFDW (Table 2). Similarly, the crude phycocyanin extract purity was 5.6 times higher with the cotton belt material, however not to food grade purity level of 0.7 without further purification (Patil et al., 2006).

Phycocyanobilin (PCB) content was evaluated solely in the biomass from the cotton belt material due to the low phycocyanin levels and purity in the biomass from the cotton rope material. The crude PCB extracts from the cotton belt material yielded an average of $0.34 \pm 0.01 \mathrm{mg} \mathrm{PCB} / \mathrm{g}$ AFDW biomass, or roughly $3.4 \mathrm{mg} \mathrm{PCB} / \mathrm{m}^{2}$ of growth surface area. This corresponds to a $13.7 \pm 0.5$ percent of theoretical yield of PCB from the LLC2 biomass, similar to those found by D. J. Chapman et al., 1967 (Cole et al., 1967) (McCarty, 2007).

Chlorophyll a extractions of the harvested biomass showed that the cotton belt material yielded nearly five times the chlorophyll a content than that of cotton rope in $\mathrm{mg} / \mathrm{g}$ of biomass (Table 2). From a growth surface area perspective, the chlorophyll a yield of the cotton belt was $79.4 \mathrm{mg} / \mathrm{m}^{2}$ and the cotton rope $47.7 \mathrm{mg} / \mathrm{m}^{2}$. When combined with the $664 \mathrm{~nm} / 665 \mathrm{~nm}$ ratios of the cotton belt and cotton rope, 1.67 versus 1.42 respectively, the overall photosynthetic physiological condition of the cotton belt biomass was superior to that of the cotton rope (Rice et al., 2005). The autotrophic index was calculated as 127 and 507 for the cotton belt and cotton rope, respectively. Values between 50 and 200 are typical of autotrophic biofilms, with higher values indicating a large consortium of heterotrophs. These results suggest that the cotton rope material supported a substantial portion of heterotrophs in the attached biofilm when compared to the cotton belt despite both materials being $100 \%$ cotton in construction.

\section{DISCUSSION}

Differences in the substratum surface characteristics may be related to the different characteristics in the recovered biomass with respect to AFDW yield, phycocyanin, autotrophic index, and chlorophyll a content. While the cotton belt provides a flat and uniform growth surface area with regard to exposure to light, the cotton rope circular diameter structure creates voids and areas with limited and no light exposure near the surface of the supporting cylinder. The limited light exposure in these areas provide an ideal sedimentation and collection area for heterotrophic bacteria, detritus, and grazers. These areas of limited light exposure are then harvested when using the spool harvester design for the cotton rope that is avoided with the flat scraper blade used in harvesting the cotton conveyor belt material.

Heterotrophic biofilms are widely documented in rotating biological contactors without exposure to a light source and are essential to many wastewater treatment processes including hydrocarbon removal, volatile organic compound control, and heavy metals remediation (Costley and Wallis, 2001; Hassard, et al., 2015; Muñoz and Guieysse, 2006; Padhi and Gokhale, 2014; Suzuki and Yamaya, 2005). With a relatively large biomass yield and both phototrophic and heterotrophic biomass zones, the rope substratum may be beneficial for operations where wastewater treatment and/or large biomass yields is the primary goal. Alternatively, the cotton belt substratum may be better suited to operations with goals of harvesting phototrophic cyanobacterial biomass in good physiological condition for downstream product development to PC, PCB, and mesobiliverdin.

It was shown that the phycocyanin content of LLC2 cyanobacteria can be modified by varying the light intensities provided during growth. The increase in phycocyanin content and purity for light limited cultures was accompanied by a lowered 
biomass productivity, which resulted in an areal phycocyanin productivity equivalent to that of high light cultures. This result has possible implications concerning a choice for phycocyanin producers with low light input and potentially lower biomass processing costs, a topic beyond the scope of this investigation.

Cotton belt growth substratum was shown to be a better choice for phycocyanin production and autotrophic presence for microalgae biofilm production in produced water. Cotton rope growth substratum showed reduced phycocyanin yield, extract purity, and chlorophyll a and also showed the presence of a large non-photosynthetic community. However, cotton rope substratum demonstrated the highest biomass yields of all 14 materials tested. The differences measured for cotton belt versus cotton rope substrata were likely due to the surface area available for light exposure and the biofilm harvesting mechanism used in this study. These results indicate producers of phycocyanin will encounter less biomass processing and phycocyanin purification costs with the use of a cotton belt growth substratum compared with a cotton rope substratum. To the best of the authors knowledge, this research is the first reported application of cyanobacteria-dominated biofilms cultured in an outdoor produced wastewater pond for the production of high value pigments.

With regard to how biofilm photobioreactor design may affect nutrient removal, the amount and rate of biomass cultivation are directly related to the uptake of nutrients including nitrogen and phosphorus. Therefore, results obtained in the testing reported in this study indicate that high light within the non-toxic range and cotton rope would be advantageous for increased nutrient removal compared with low light and cotton belt for biofilm cultivation. However, the physical appearance of both substrata at the termination of testing indicated that the cotton belt was more durable than the cotton rope, which appeared more frayed from harvesting and possible heterotrophic biodegradation of the cotton matrix than the cotton belt.

With regard to wastewater management, the produced water tested in this study contained low levels of metals and organic chemicals that are able to be tolerated and treated with microalgae and, when dissolved solids or salinity is high, utilize pre-treatment including suspended solids or colloidal materials (Rahman et al., 2020). The salinity of the produced water at $19,700 \mathrm{umhos} / \mathrm{cm}$ can be a challenge for reuse applications in irrigation.

In conclusion, the ideal management factors found in this study for phycocyanin production maximization from LLC2 cyanobacteria dominated biofilms treating produced wastewater are to use low light levels and a cotton belt substratum for cultivation. A tradeoff exists between high light with associated low phycocyanin content and high biomass productivity and low light with associated high phycocyanin content and low biomass productivity.

Phycocyanin and phycocyanobilin and its derivatives have possible applications as antioxidants, anti-inflammatories, fluorescent labels, and coloring agents (Eriksen, 2008; Hirata et al., 2000; Sekar and Chandramohan, 2007). Phycocyanobilin can be converted to mesobiliverdin IX which has similar cytoprotective and therapeutic potential as its close analog, biliverdin IX (Ito, et al., 2013). High value phycocyanin and phycocyanobilin, after additional purification, may help offset wastewater treatment costs, or provide a revenue stream for produced water disposal operations.

Results obtained by other researchers testing algae-based biofilm systems for municipal wastewater (Gross and Wen, 2014) and a comprehensive review of produced water as a platform for biomass and biofuel production in by Rahman et al. (2020) have not involved biofilm treatment of produced water. Therefore, there exists a need for more research to evaluate treatment and valorization of produced water using algae biofilm-based engineering systems.

Based on the results of this study, future studies should be conducted to assess other high value products, such as other phycobiliproteins, pigments, and metabolites from microalgae based biofilms cultured in produced water. Analysis of downstream purification and potential contaminants should be evaluated for produced wastewater cultured microalgae bioproducts. Investigations addressing salt stress/accumulation will be important to scale up optimization. Additionally, the potential value of cyanobacteria based biofilms for value bioproducts in terms of biofuels, fertilizer, feed, and biogas potential should be assessed.

\section{DATA AVAILABILITY STATEMENT}

The raw data supporting the conclusion of this article will be made available by the authors, without undue reservation.

\section{AUTHOR CONTRIBUTIONS}

JW, graduate student, planned and executed the testing, experiments, and interpretation of results, and also developed and wrote the manuscript. JT, faculty, developed the procedure for phycocyanin (PC) extraction from LLC2 and procedure for measurement of PC yield and productivity, and assisted in the technical editing of the manuscript. RS, faculty, developed the RABR technology and strategy for testing with LLC2, assisted with the characterization of LLC2, and provided input to the statistical design and interpretation of results.

\section{ACKNOWLEDGMENTS}

The authors would like to thank the Environmental Department of the City of Logan, Utah (Contract \#090203), the Utah Water Research Laboratory (Contract \#WR-1089), and the Huntsman Environmental Research Center (Grant \#A17779) for providing financial and material support for this study. We would like to acknowledge the support of the Utah Science Technology and Research (USTAR) initiative, the Sustainable Waste to Bioproducts Engineering Center (SWBEC), and Dong Chen for the generous access to laboratory facilities, infrastructure, and ongoing support. We thank Jacob Watkins, DOE Pacific Northwest National Laboratory Engineer Intern (SULI), for technical review and input to improve the communication and for formatting assistance. Biological engineering students Alan Hodges, Tyler Gladwin, and Cody Maxfield are acknowledged for their supporting functions and technical discussions. 


\section{REFERENCES}

Arriada, A. A., and Abreu, P. C. (2014). Nannochloropsis Oculata Growth in Produced Water: an Alternative for Massive Microalgae Biomass Production. Braz. J. Pet. Gas 8, 119-125. doi:10.5419/bjpg2014-0011

Bennet, A., and Bogorad, L. (1973). Complementary Chromatic Adaptation in a Filamentous Blue-green Alga. J. Cel Biol. 58, 419-435. doi:10.1083/jcb.58.2.419

Blanken, W., Janssen, M., Cuaresma, M., Libor, Z., Bhaiji, T., and Wijffels, R. H. (2014). Biofilm Growth ofChlorella Sorokinianain a Rotating Biological Contactor Based Photobioreactor. Biotechnol. Bioeng. 111, 2436-2445. doi:10.1002/bit.25301

Chaneva, G., Furnadzhieva, S., Minkova, K., and Lukavsky, J. (2007). Effect of Light and Temperature on the Cyanobacterium Arthronema Africanum - A Prospective Phycobiliprotein-Producing Strain. J. Appl. Phycol. 19, 537-544. doi:10.1007/s10811-007-9167-6

Chew, K. W., Yap, J. Y., Show, P. L., Suan, N. H., Juan, J. C., Ling, T. C., et al. (2017). Microalgae Biorefinery: High Value Products Perspectives. Bioresour. Tech. 229, 53-62. doi:10.1016/j.biortech.2017.01.006

Christenson, L. B., and Sims, R. C. (2012). Rotating Algal Biofilm Reactor and Spool Harvester for Wastewater Treatment with Biofuels By-Products. Biotechnol. Bioeng. 109, 1674-1684. doi:10.1002/bit.24451

Clark, C., and Veil, J. (2015). Produced Water Volumes and Management Practices. Groundw. Prot. Counc. 119.

Cole, W. J., Chapman, D. J., and Siegelman, H. W. (1967). Structure of Phycocyanobilin. J. Am. Chem. Soc. 89, 3643-3645. doi:10.1021/ja00990a055

Cornejo, J., Beale, S. I., Terry, M. J., and Lagarias, J. C. (1992). Phytochrome Assembly. The Structure and Biological Activity of 2(R),3(E)phytochromobilin Derived from Phycobiliproteins. J. Biol. Chem. 267, 14790-14798. doi:10.1016/s0021-9258(18)42109-6

Costley, S., and Wallis, F. M. (2001). Bioremediation of Heavy Metals in a Synthetic Wastewater Using a Rotating Biological Contactor. Water Res. 35, 3715-3723. doi:10.1016/s0043-1354(01)00072-0

A. D. Eaton, L. S. Clesceri, E. W. Rice, and A. E. Greenberg (Editors) (2005). Standard Methods for the Examination of Water and Wastewater. 21st ed. (Washington, D.C: American Public Health Association).

Eriksen, N. T. (2008). Production of Phycocyanin-A Pigment with Applications in Biology, Biotechnology, Foods and Medicine. Appl. Microbiol. Biotechnol. 80, 1-14. doi:10.1007/s00253-008-1542-y

Godfrey, V. (2012). Production of Biodiesel from Oleaginous Organisms Using Underutilized Wastewaters. [dissertation/master's thesis]. Logan (UT)]: Utah State University.

Gross, M., Henry, W., Michael, C., and Wen, Z. (2013). Development of a Rotating Algal Biofilm Growth System for Attached Microalgae Growth with In Situ Biomass Harvest. Bioresour. Tech. 150, 195-201. doi:10.1016/j.biortech.2013.10.016

Gross, M., and Wen, Z. (2014). Yearlong Evaluation of Performance and Durability of a Pilot-Scale Revolving Algal Biofilm (RAB) Cultivation System. Bioresour. Tech. 171, 50-58. doi:10.1016/j.biortech.2014.08.052

Hassard, F., Biddle, J., Cartmell, E., Jefferson, B., Tyrrel, S., and Stephenson, T. (2015). Rotating Biological Contactors for Wastewater Treatment - a Review. Process Saf. Environ. Prot. 94, 285-306. doi:10.1016/j.psep.2014.07.003

Hirata, T., Tanaka, M., Ooike, M., Tsunomura, T., and Sakaguchi, M. (2000). Antioxidant Activities of Phycocyanobilin Prepared from Spirulina Platensis. J. Appl. Phycol. 12, 435-439. doi:10.1023/a:1008175217194

Ito, T., Chen, D., Chang, C.-W. T., Kenmochi, T., Saito, T., Suzuki, S., et al. (2013). Mesobiliverdin IXa Enhances Rat Pancreatic Islet Yield and Function. Front. Pharmacol. 4, 50. doi:10.3389/fphar.2013.00050

Marín-Prida, J., Pavón-Fuentes, N., Llópiz-Arzuaga, A., Fernández-Massó, J. R., Delgado-Roche, L., Mendoza-Marí, Y., et al. (2013). Phycocyanobilin Promotes PC12 Cell Survival and Modulates Immune and Inflammatory Genes and Oxidative Stress Markers in Acute Cerebral Hypoperfusion in Rats. Toxicol. Appl. Pharmacol. 272, 49-60. doi:10.1016/j.taap.2013.05.021

McCarty, M. F. (2007). Clinical Potential ofSpirulinaas a Source of Phycocyanobilin. J. Med. Food 10, 566-570. doi:10.1089/jmf.2007.621
Muñoz, R., and Guieysse, B. (2006). Algal-bacterial Processes for the Treatment of Hazardous Contaminants: a Review. Water Res. 40, 2799-2815. doi:10.1016/j. watres.2006.06.011

Padhi, S. K., and Gokhale, S. (2014). Biological Oxidation of Gaseous VOCs Rotating Biological Contactor a Promising and Eco-Friendly Technique. J. Environ. Chem. Eng. 2, 2085-2102. doi:10.1016/j.jece.2014.09.005

Patil, G., Chethana, S., Sridevi, A. S., and Raghavarao, K. S. M. S. (2006). Method to Obtain C-Phycocyanin of High Purity. J. Chromatogr. A 1127, 76-81. doi:10. 1016/j.chroma.2006.05.073

Polyzois, A., Kirilovsky, D., Dufat, T.-h., and Michel, S. (2020). Effects of Modification of Light Parameters on the Production of Cryptophycin, Cyanotoxin with Potent Anticancer Activity, in Nostoc Sp. Toxins 12 (12), 809. doi:10.3390/toxins12120809

Rahman, A., Agrawal, S., Nawaz, T., Pan, S., and Selvaratnam, T. (2020). A Review of Algae-Based Produced Water Treatment for Biomass and Biofuel Production. Water 12 (9), 2351. doi:10.3390/w12092351

Rice, E. W., Baird, R. B., and Eaton, A. D. (2005). Standard Methods for the Examination of Water and Wastewater.

Rito-Palomares, M., Nuñez, L., and Amador, D. (2001). Practical Application of Aqueous Two-phase Systems for the Development of a Prototype Process for C-Phycocyanin Recovery fromSpirulina Maxima. J. Chem. Technol. Biotechnol. 76, 1273-1280. doi:10.1002/jctb.507

Sebestyén, P., Blanken, W., Bacsa, I., Tóth, G., Martin, A., Bhaiji, T., et al. (2016). Upscale of a Laboratory Rotating Disk Biofilm Reactor and Evaluation of its Performance over a Half-Year Operation Period in Outdoor Conditions. Algal Res. 18, 266-272. doi:10.1016/j.algal.2016.06.024

Sekar, S., and Chandramohan, M. (2007). Phycobiliproteins as a Commodity: Trends in Applied Research, Patents and Commercialization. J. Appl. Phycol. 20, 113-136. doi:10.1007/s10811-007-9188-1

Sullivan Graham, E. J., Dean, C. A., Yoshida, T. M., Twary, S. N., Teshima, M., Alvarez, M. A., et al. (2017). Oil and Gas Produced Water as a Growth Medium for Microalgae Cultivation: A Review and Feasibility Analysis. Algal Res. 24, 492-504. doi:10.1016/j.algal.2017.01.009

Suzuki, T., and Yamaya, S. (2005). Removal of Hydrocarbons in a Rotating Biological Contactor with Biodrum. Process Biochem. 40, 3429-3433. doi:10. 1016/j.procbio.2005.04.001

Winckelmann, D., Bleeke, F., Thomas, B., Elle, C., and Klöck, G. (2015). Open Pond Cultures of Indigenous Algae Grown on Non-arable Land in an Arid Desert Using Wastewater. Int. Aquat. Res. 7, 221-233. doi:10.1007/s40071-015-0107-9

Wood, J. L., Miller, C. D., Sims, R. C., and Takemoto, J. Y. (2015). Biomass and Phycocyanin Production from Cyanobacteria Dominated Biofilm Reactors Cultured Using Oilfield and Natural Gas Extraction Produced Water. Algal Res. 11, 165-168. doi:10.1016/j.algal.2015.06.015

Zhao, K.-H., Su, P., Li, J., Tu, J.-M., Zhou, M., Bubenzer, C., et al. (2006). Chromophore Attachment to Phycobiliprotein $\beta$-Subunits. J. Biol. Chem. 281, 8573-8581. doi:10.1074/jbc.M513796200

Conflict of Interest: The authors declare that the research was conducted in the absence of any commercial or financial relationships that could be construed as a potential conflict of interest.

Publisher's Note: All claims expressed in this article are solely those of the authors and do not necessarily represent those of their affiliated organizations, or those of the publisher, the editors and the reviewers. Any product that may be evaluated in this article, or claim that may be made by its manufacturer, is not guaranteed or endorsed by the publisher.

Copyright (c) 2022 Wood, Takemoto and Sims. This is an open-access article distributed under the terms of the Creative Commons Attribution License (CC $B Y)$. The use, distribution or reproduction in other forums is permitted, provided the original author(s) and the copyright owner(s) are credited and that the original publication in this journal is cited, in accordance with accepted academic practice. No use, distribution or reproduction is permitted which does not comply with these terms. 